Cesaris." It was also the first volume of a series of ephemerides which have been since continued without interruption.

In 1799 the publication of the Portuguese ephemerides commenced - "Ephemerides astronomicas calculadas para o meridiano Observatorio nacional de universidade de Coimbra, para uso do mesmo Observatorio, e para o da navegacao Portugueza."

Lastly, in 1756 , appeared the ephemerides of Vienna :"Ephemerides astronomica anni 1757 , ad meridianum Vindobonensem jussu Augustorum calculis a Mlaximiliano Hell. Casario regio astronomo et Mechanicus experimentalis professore publico et ordinis," which were continued by Triesmecker. The Ephemerides of Vienna were constructed upon the model of the Abbé de la Caille, much more than upon that of the Connaissance des Temps. MIorcover, at this period, the Ephemerides of La Caille were almost exclusively employed by French astronomers.

(To be continued.)

\section{THE BRIGHTON AQUARIUM}

$\mathrm{N}$ accordance with an intention entertained previous to $I$ resigning the tenure of my office as Curator to the Brighton Aquarium, I propose to give a brief outline of the plan of construction and general system of arrangements obtaining in that institution.

The Brighton Aquarium, while emulated by several buildings of a similar nature, in different parts of the kingdom and on the Continent, still holds its own in being on a scale of magnitude hitherto unsurpassed, more than one of its tanks, in illustration of this, being of sufficient size to accommodate the evolutions of porpoises and other small Cetacex. The architect and originator of the undertaking, Mr. Edward Birch, well known as the engineer of the new picr at Hastings, entertained the idea of constructing this Aquarium as long agro as the year 1866 when visiting the one on a small scale then existing at Boulogne; Brighton was selected as a site on account of its proximity to the sea-coast and its great popularity as a place of resort. The works were commenced in the autumn of the year 1869 , but owing to various interruptions the building was not formally thrown open to the public until August 1872 , the ceremony taking place during the week in which the members of the British Association honoured Brighton as their place of meeting.

The area occupied by the Brighton Aquarium averages 715 fect in length by 100 feet in width, running east and west along the shore line between the sea and the Marine Parade; the principal entrance is at the west end facing the castern angle of the Royal Albion Hotel. The building internally is divided into two corridors separated from one another by a fernery and considerable interspace. The approach to the first or Western corridor is gained through a spacious entrance-hall supplied with readingtables, and containing between the pillars which support the roof portable receptacles of sea-water for the display of small marine specimens that would be lost to sight in the larger tanks.

The tanks for ordinary exhibition commence with No. I on the left side of the western corridor, and, as shown in the ground-plan, follow in consecutive order round the two corridors, the last, No. $4 \mathrm{r}$, immediately facing No. $\mathrm{I}$. The smallest of these tanks measures in feet long by 10 feet broad, and is capable of holding some 4,000 gallons of water, while the largest, No. 6 , in the western corridor, and the subject of the accompanying engraving, presents a total frontage, including the two angles of 130 feet, with a greatest width of 30 feet, and contains no less than yo,000 gallons. Every gradation of size occurs between these two extremes, the depth of the water in all ranging from 5 to 6 feet. Supplementary to the foregoing, a series of half-a-dozen shallow octagonal table-tanks occupies a portion of the interspace between the two corridors, these being especially adapted for the exhibition of animals such as starfish, anemones, and others seen to best advantage when viewed perpendicularly through the water. Flanking one side of this same interspace are several ponds fenced off for the reception of seals and other amphibious mammalia and larger Reptilia, while at its further or eastern extremity artistic rock-work runs to a height of 40 feet, thickly planted with chroice ferns and suitable exotic plants, and broken in its course by a picturesque waterfall and stream. Tanks 12 to 17 in the eastern corridor, in addition to the stream and basin beneath the waterfall, are set apart for the exclusive exhibition of fresh-water fish, the remaining tanks being devoted to marine species. The bulk of water thus utilised in the fresh and sea-water tanks collectively amounts to 500,000 gallons, and in addition to this several smaller store tanks in the Naturalists' Room, adjoining the eastern corridor, afford accommodation for reserve stock, or for new arrivals before their display to public view.

The style of architecture dominant throughout the building is Italian and highly ornate, the arched roof of the corridors being groined and constructed of variegated bricks, supported on columns of Bath stone, polished serpentine marble, and Aberdeen granite; the capital of cach column is elaborately carved in some appropriate marine device, while the floor in correspondence is laid out in acrostic tiles. The divisions constituting the fronts of the tanks are composed each of three sheets of plate glass, each plate having a thickness of one inch, and measuring six feet high by three feet wide, separated from one another and supported centrally by upright massive iron mullions; in the smallest tanks the front is represented by but one of these divisions, while that of the largest, No. 6, consists of as many as eleven. Among other conspicuous structural features of the aquarium demanding notice are the huge masses of rock cntering into the composition of the tanks and fernery. Part of these are composed of porous tufa brought from Derbyshire, while the remaining and greater portion presents the appearance at first sight of old Red Sandstone of the Devonian epoch. This latter, however, is entirely artificial, being built up of smaller nondescript fragments, faced with cement and coloured sand, though so true to Nature have the boulders been fashioned and stratigraphically arranged, that more than one eminent geologist has been deceived by their aspect, and it is difficult in looking into the larger tanks to get rid of the impression that some of the miniature picturesque coves characteristic of the Devonshire coast have been transported bodily to Brighton.

The system adopted at the Brighton Aquarium for continually renewing the supply of oxygen necessary for the well-being of the animals agrees with that followed at Berlin, streams of compressed air being constantly forced into the tanks through vulcanite tubes carried to the bottom of the water, and each tank being fitted with a greater or less number of these tubes according to its size. Following the same principle there is no true circulation, each tank being distinctly independent and the same water rcmaining in it perpetually unless required to be changed on account of turbidity, an accident such as the cracking of a front glass, or for altering the arrangement of the inhabitants. In such cases the tanks are refilled from four large reservoirs situated beneath the corridors, holding in aggregate a quantity approximating but not exceeding that contained in the tanks above, and into which the water is first pumped by a six-horse power centrifugal engine direct from the sea, and thence conveyed by the same force to the tanks, through a main extending round the building.

The system above described, while practical in aquaria at the seaside, where the supply of water is unlimited, does not answer inland, as exemplified in the decadence, 
from a scientific point, of the one from which that at Brighton is copied, and even in the former case is associated with serious drawbacks and disadvantages, which forbid it from yielding in compensation for the outlay and labour expended the results realised by those constructed on later and more approved principles. It is impossible, for instance, to keep in health at the Brighton Aquarium the number of fish in comparison to the size of any given tank as will be found in the aquarium at the Crystal Palace or that of Hamburgh, or Copenhagen, or any other constructed on the same principle, though at the same time it is essential to remark, that lately the capabilities of the Brighton tanks have not been turned to their greatest advantage, as instanced in No. 6 , holding I 0,000 gallons of water, which for many weeks past has been occupied by but three dogfish, a ray, and a few turtle ; No. II, with 9,000 gallons, by two mackerel, ;and so on. A remaining still greater source of dissatisfaction associated with the non-circulatory system, and yet one capable, perhaps, of full appreciation by those only who have held practical aquarium responsibility, arises from the difficulty, verging upon the impossibility, of maintaining the tanks uniformly bright and clear throughout the building. Some fish foul the water to a much greater extent than others, notably the Flat-fish or Pleuronectidx, who in a few weeks will render a clear isolated tank too opaque for the opposite side some twenty feet distant to be discerned. The only existing remedy for such a case is to run off the water and supply fresh from the reservoirs beneath; but this water being drawn from the shore-line, the feeding pipe remaining exposed at half tide, is necessarily loaded with impurities, which rc-agitated by the action of pumping involves the lapse of several more days before the tank is in a fit state for exhibition. At the suggestion of my predecessor, the late Mr. J. K. Lord, oysters and other bivalve mollusca were introduced into the tanks for the purpose of removing the organic particles which rendered the water turbid, but though these have proved of great service, the root of the evil remains undisturbed, and it is only by the application of the circulatory system, securing with it the more thorough oxygenisation of the water, that the problem is to be effectually solved.

This system, initiated by Mr. WV. A. Lloyd at the Hamburgh Aquarium, and now maintained under his personal superintendence at the Crystal Palace, consists in having, in the first place, a bulk of water in the reservoirs beneath exceeding by four or five times the total amount contained in the tanks above, and which, being pumped up by steam power and circulated through the building, takes up in its course by exposure to the atmosphere an amount of oxygen, permitting the preservation in health not only of a much larger number of inhabitants to each tank, but at the same time communicates to the water a degree of clearness and brilliancy unattainable by other means, and which brilliancy is increased or diminished in exact proportion to the uniformity and force of the current s s maintained. One theoretical objection urged by the architect of the Brighton Aquarium against the circulatory system, is that in the event of paint or other deleterious substance falling into any one tank the water of the neighbouring tanks would suffer equally. Practically, such mishaps have no business to occur, and though in such a case, on the "siphon" mode of circulation first attempted but abandoned as impractical at Brighton, some mischief might be done, it would be impossible under that to be presently suggested as still feasible at the institution here under consideration, and until the adoption of which the Brighton Aquarium cannot be expected to fully realise the highest anticipations of its promoters, while the greater or less turbidity of its tanks must continue as hitherto a constant source of dissatisfaction to the directors, and of anxicty and mortification to the officcrs hald responsible.

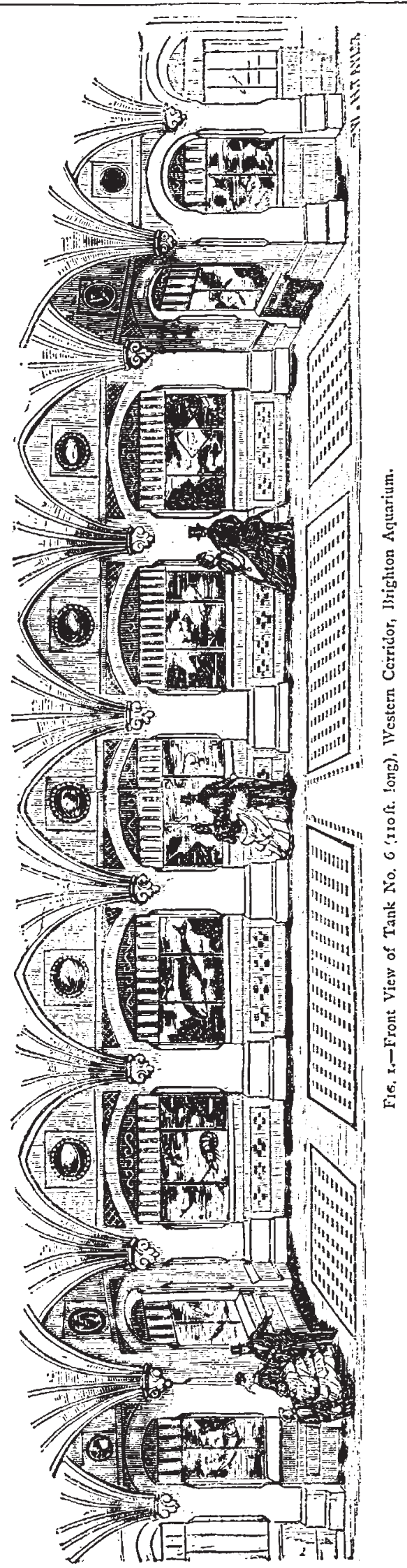




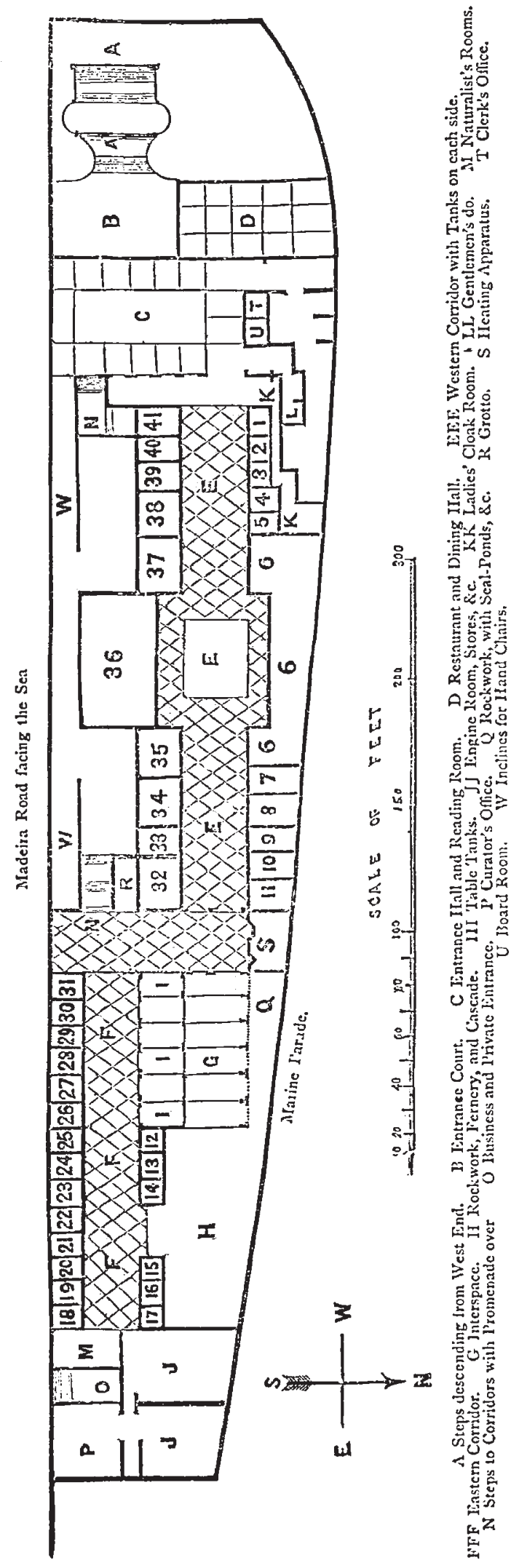

At the castern extremity of the building there is still a considerable plot of ground unutilised belonging to the company; admirably adapted for the construction of a supplementary reservoir, holding, say, one million and a half gallons, and whose contents, added to those of the existing ones, would yield a body of water sufficient for the purpose. This ground, in fact, being considerably above the level of the tanks, would permit of simplifying matters by pumping the water up from the existing reservoirs to the proposed new one, whence it would circulate through the tanks and return to its original source by the mere force of gravitation. As now the individuality of each tank might be maintained, the water flowing from the main through the existing cocks, and escaping to the reservoirs bencath, through the same overflows, two or more of which are supplied to cach tank, which might be enlarged or further multiplied, if requisite to carry off the accelerated stream. Should any tank now become unduly turbid through unforseen circumstances, the accident could be immediately remedied by emptying it into the large reservoirs bencath where so small a quantity in proportion would effect no appreciable alteration, the tank being refilled through the main; while in the event of paint or other poisonous ingredient being upset the water would be run off to waste as under existing circumstances. An important and essential preliminary step to thesc proposed alterations will, however, be to render the existing reservoirs watertight, their present defective condition in this respect being one of the chief obstacles to the storage of clear water, which in an inland aquarium would have simply proved the ruin of the undertaking. These difficulties surmounted, and the reservoirs filled with water drawn from some little distance off shore, saylat the head of the pier close by, and so free from the chalky wash and innumerable organic impurities inseparable from the present supply, the aquarium will be entirely independent of the sea, and much waste of labour now occupied in pumping from it saved. The still more important results accruing to the institution through the uniform clearness of the water, and the capability of each tank to support a number of inhabitants compatible to its size, cannot be overrated. *

Under any circumstances, it the remedy here proposed is not adopted, it is to be trusted that the weak points of the Brighton Aquarium here noticed will prove sufficient to prevent the repetition of the same errors of construction in any of the Aquaria now in contemplation or being built in this country. On the Continent, the type initiated by our own countryman at Hamburgh, and at the Crystal Palace, with such improvements as practical experience dictates, is almost invariably adopted, and it is incumbent that England, as the initiator of the movement, should maintain her lead. So far, from its size and its proximity to the sea, the Brighton Aquarium has been able to achieve results unrealised by any other institution of its description, as instanced in the recent preservation in its tanks of creatures so large as porpoises, and fish so delicately constituted as herrings and mackerel ; but these results are by no means commensurate with the expenditure involved in its establishment, and we hope steps will be forthwith taken to remedy the defects indicated.

The Isle of Vight and the Devonshire coast, especially Torquay, are localities offering far greater advantages than Brighton, as zoological stations for the acquisition of specimens, and now that the financial success of large Aquaria under judicious management in centres of sufficient population is well established, the temptation thesc places offer to an enterprising company cannot be long resisted.

IV. SAVILLE KENT

- Defects of construction in the Brighton Aquarium likely to interfere with the future efficiency of the establishment were alluded to without specification, while the building was in the bands of the contractor.-See NATURE, vol. iv. P. 394 . 